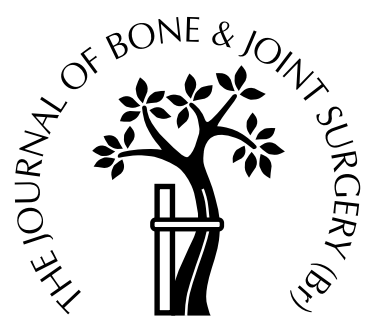

\title{
Painful soft-tissue reaction to injectable Norian SRS calcium phosphate cement after curettage of enchondromas
}

\author{
Heike Welkerling, Johann Raith, Norbert Kastner, Claus Marschall, \\ Reinhard Windhager \\ From the University of Graz, Austria
}

\begin{abstract}
A prospective single-cohort study was designed to include 20 patients with enchondromas but was stopped because of poor early results. Four patients with an enchondroma, three in the proximal humerus and one in the distal femur, were treated by curettage and filling of the defect with Norian SRS cement. Clinical and radiological follow-up including CT and MRI was carried out for 18 months. All three patients with lesions in the proximal humerus had severe pain and limited movement of the shoulder. The radiological and CT appearances of the cement were unchanged at follow-up. There were characteristic appearances of synovitis and periosteitis on MRI in two patients. Since the cement induces a soft-tissue reaction the bony cavity should be sealed with the curetted and burred bone after curettage and introduction of Norian cement, especially in sites where a tourniquet cannot be applied.
\end{abstract}

J Bone Joint Surg [Br] 2003;85-B:238-9.

Received 13 February 2002; Accepted after revision 9 July 2002

Norian SRS calcium phosphate cement is an injectable biocompatible bone substitute. Its use avoids morbidity at the donor site after harvesting. The cement may be resorbed in time and it has a high compressive strength of $55 \mathrm{MPa}^{1}{ }^{1}$ In this prospective study we have investigated its clinical performance, the interval between its introduction and resorption and evidence of bone remodelling in the treatment of benign bone tumours.

H. Welkerling, MD

N. Kastner, MD

C. Marschall, MD

R. Windhager, MD

Department of Orthopaedic Surgery

J. Raith, MD

Department of Radiology

University of Graz, LKH Graz, Auenbruggerplatz 9a, A-8036 Graz, Austria.

Correspondence should be sent to Dr R. Windhager.

(C)2003 British Editorial Society of Bone and Joint Surgery doi.10.1302/0301-620X.85B2.13255\$2.00 $\underline{\text { Patients and Methods }}$

A prospective single cohort study was designed to include 20 patients with an enchondroma but because of poor clinical results was stopped after four treatments.

After giving their informed consent and establishing the diagnosis of an enchondroma by biopsy, four patients were treated by curettage and filling of the cavity with Norian cement. In three the tumour was in the proximal humerus and in one in the distal femur. Clinical and radiological review was undertaken after 6 weeks and 3, 6, 12 and 18 months. MRI was performed at 3,6 and 18 months and CT at 3, 9 and 18 months. Pain was measured using a visual analogue scale (VAS). The pattern of the cement and the remodelling of bone were assessed on CT. Gadoliniumenhanced MRI was used to assess changes in the formation of oedema with time.

Results

In contrast to the patient with an enchondroma of the distal femur, those with lesions in the proximal humerus had pain for up to nine months after operation with pain levels of 6,7 and 8 , and were unable to work for six months.

All three patients had limited movement of the shoulder with abduction restricted to $90^{\circ}$ during the first three months. After follow-up for nine months, there was a dramatic improvement in the movements of the shoulder. Lowgrade infection was excluded in all cases by measurement of the inflammatory markers. There was no change in the radiological or CT appearance of the cement at 18 months in all cases except one (Fig. 1).

On MRI, in one case, there were changes suggestive of oedema of the capsule of the shoulder at six months. These were thought to be due to synovitis. In another patient there was periosteal oedema around the proximal humerus between six and nine months and this was thought to be caused by periosteitis (Fig. 2).

\section{Discussion}

Norian SRS calcium phosphate cement has been used successfully in the treatment of fractures of the hip, the distal radius and the calcaneum. It has also been used in animal 


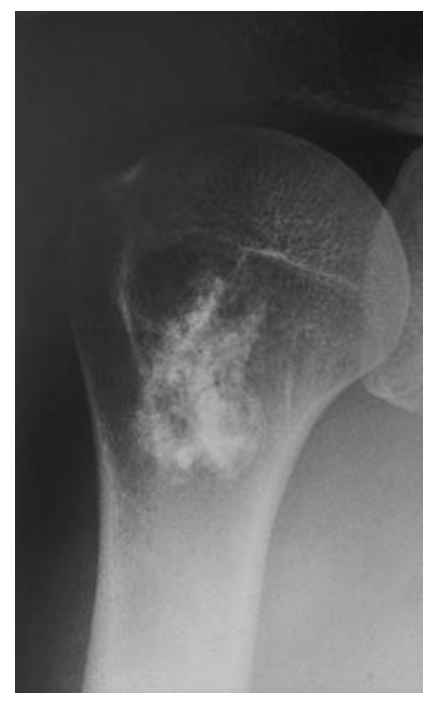

Fig. 1a

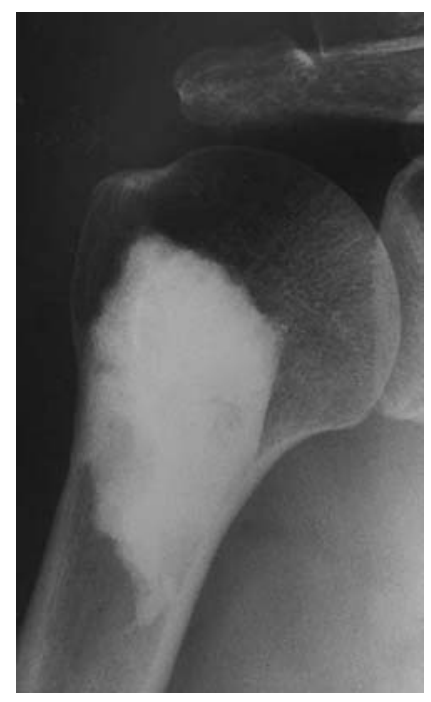

Fig. 1b

Radiographs showing a) an enchondroma in the proximal humerus, and b) 18 months after curettage and filling the defect with Norian cement. The cement is unchanged.

and cadaver studies. ${ }^{1-7}$ Incomplete resorption after six months has been reported in animal studies. ${ }^{2}$ In the present investigation the appearances of the cement were unchanged 18 months after the operation.

The satisfactory introduction of the cement is hampered by bleeding from the bony cavity and is thus easier in sites where a tourniquet may be used. The paste adheres to the soft tissues and is difficult to remove. The cement appears to induce an inflammatory reaction in the soft tissues.

In contrast to the patient with the lesion in the distal femur in whom a tourniquet had been applied, those with an enchondroma in the proximal humerus had severe pain and a poor range of movement. In two there were signs of synovitis and periosteitis. Pain and function improved rapidly after six months when new bone began to form over the defect.

No histological evidence of an adverse foreign-body reaction was reported by Constantz et $\mathrm{al}^{8}$ whereas Miyamoto et $\mathrm{al}^{9}$ described a severe inflammatory response after implantation of conventional calcium phosphate cement into the subcutaneous tissue of rats. Lobenhoffer ${ }^{10}$ described extrusion of cement from proximal tibial fractures causing wound breakdown in two of nine cases.

Formal closure of the cavity by bone after the introduction of the cement may prevent this complication.

No benefits in any form have been received or will be received from a commercial party related directly or indirectly to the subject of this article.

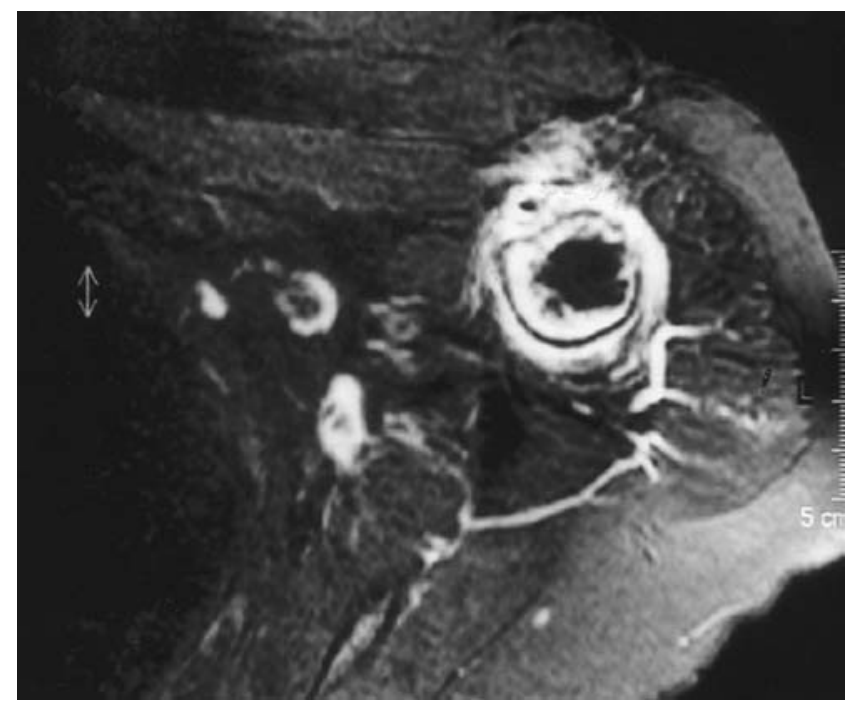

Fig. 2

An axial T2-weighted MR scan of the proximal humerus three months after treatment. There is oedema around the proximal humerus which was thought to be due to periosteitis.

\section{References}

1. Goodman SB, Bauer TW, Carter D, et al. Norian SRS cement augmentation in hip fracture treatment: laboratory and initial clinical results. Clin Orthop 1998;348:42-50.

2. Frankenburg EP, Goldstein SA, Bauer TW, Harris SA, Poser RD. Biomechanical and histological evaluation of a calcium phosphate cement. J Bone Joint Surg [Am] 1998;80-A:1112-24.

3. Kopylov P, Runnqvist K, Jonsson K, Aspenberg P. Norian SRS versus external fixation in redisplaced distal radial fractures: a randomised study in 40 patients. Acta Orthop Scand 1999;70:1-5

4. Sanchez-Sotelo J, Munuera L, Madero R. Treatment of fractures of the distal radius with a remodellable bone cement: a prospective, randomised study using Norian SRS. J Bone Joint Surg [Br] 2000;82B:856-63.

5. Schildhauer TA, Bennett AP, Wright TM, Lane JM, O'Leary PF. Intravertebral body reconstruction with an injectable in situ-setting carbonated apatite: biomechanical evaluation of a minimally invasive technique. J Orthop Res 1999;17:67-72.

6. Schildhauer TA, Bauer TW, Josten C, Muhr G. Open reduction and augmentation of internal fixation with an injectable skeletal cement for the treatment of complex calcaneal fractures. J Orthop Trauma 2000;14:309-17.

7. Yetkinler DN, Ladd AL, Poser RD, Constanz BR, Carter D. Biomechanical evaluation of fixation of intra-articular fractures of the distal part of the radius in cadavera: Kirschner wires compared with calciumphosphate bone cement. J Bone Joint Surg [Am] 1999;81-A:391-9.

8. Constantz BR, Barr BM, Ison IC, et al. Histological, chemical, and crystallographic analysis of four calcium phosphate cements in different rabbit osseous sites. J Biomed Mater Res 1998;43:451-61.

9. Miyamoto Y, Ishikawa K, Takechi M, et al. Histological and compositional evaluations of three types of calcium phosphate cements when implanted in subcutaneous tissue immediately after mixing. J Biomed Mater Res 1999;48:36-42.

10. Lobenhoffer P. Minimally invasive knee joint surgery. Zentralbl Chir 1997;122:974-85. 